\title{
Influence of crystalline structure on the luminescence properties of terbium orthotantalates
}

\author{
Kisla P.F. Siqueira ${ }^{\mathrm{a}}$, Alexandre P. Carmo ${ }^{\mathrm{b}}$, Maria J.V. Bell ${ }^{\mathrm{c}}$, Anderson Dias ${ }^{\mathrm{a}, *}$ \\ ${ }^{a}$ Departamento de Química, Universidade Federal de Ouro Preto, Campus Morro do Cruzeiro, ICEB II, Ouro Preto 35400-000, Minas Gerais, Brazil \\ ${ }^{\mathrm{b}}$ Instituto Federal Fluminense, Campus Cabo Frio, RJ 28909-971, Brazil \\ ' Departamento de Física, Universidade Federal de Juiz de Fora, Juiz de Fora 36036-330, MG, Brazil
}

\section{A R T I C L E I N F O}

Article history:

Received 22 October 2012

Received in revised form

30 January 2013

Accepted 6 February 2013

Available online 14 February 2013

Keywords:

Terbium orthotantalates

Luminescence

Crystal structures

Spectroscopic properties

\begin{abstract}
A B S T R A C T
Terbium orthotantalate powders were produced with $\mathrm{M}$-fergusonite type (I2/a) and $\mathrm{M}^{\prime}$-fergusonite type (P2/a) structures. The samples were studied by X-ray diffraction, Raman scattering, and photoluminescence measurements (emission and decay curves). The results showed that crystalline materials were obtained with all the 18 Raman-active modes predicted by group theory calculations. Also, it was observed through photoluminescence decay curves that the $\mathrm{Tb}^{3+}$ ions occupies only onesymmetry site in both crystallographic arrangements. Photoluminescence emission curves exhibited some variation in spectral shape, peak position, and relative intensity as a consequence of their different crystalline arrangements. The dominated emission of $\mathrm{Tb}^{3+}\left({ }^{5} \mathrm{D}_{4} \rightarrow{ }^{7} \mathrm{~F}_{5}\right)$ is centered with a maximum intensity at $549.2 \mathrm{~nm}$ (M-type) and $543.0 \mathrm{~nm}$ (M'-type). Fluorescence lifetimes for $\mathrm{M}-\mathrm{TbTaO}_{4}$ and $\mathrm{M}^{\prime}-\mathrm{TbTaO}_{4}$ were determined as $33.4 \mu$ s and $1.25 \mathrm{~ms}$, respectively. $\mathrm{M}^{\prime}$-type materials seems to be the most suitable for luminescent devices and could be a potential green luminescent material due to the strongest emission if compared with the M-fergusonite type.
\end{abstract}

(c) 2013 Elsevier B.V. All rights reserved.

\section{Introduction}

The development of luminescent inorganic materials has been subject of extensive research in the past years because of their applications in devices involving the artificial production of light [1]. In this respect, rare earths are good candidates for luminescence center due to their special $4 \mathrm{f}$ intra-shell transitions [2]. Particularly, terbium ions are widely used as efficient emission centers in many oxide-based compounds, having relatively high transition probabilities originating from the $4 \mathrm{f}$ electron configuration [3]. The strong green emission with high glow purity and stability make terbiumdoped phosphors to be suitable for many technological applications, such as cathode-ray tubes, fluorescence lamps, X-ray image devices, scintillators, light emitting diodes, and field emission displays [4]. Then, a large number of studies have been devoted to terbiumdoped oxide matrices [5-12]. Among them, $\mathrm{Tb}^{3+}$ activated tantalates have attracted much attention because it is a promising alternative phosphor for X-ray intensifying screen [13]. The fluorescent properties of rare earth tantalates and niobates were firstly reported in [14]. Undoped tantalates and niobates themselves have been well known as self-activated luminescent materials [15]. Nevertheless, to the best of our knowledge, no work concerning terbium orthotantalates in self-activated materials was previously reported in the literature so far.

\footnotetext{
* Corresponding author. Tel.: +55 31 35591716; fax: +55 3135591707 .

E-mail addresses: anderson_dias@iceb.ufop.br, anderson_dias@ig.com.br (A. Dias).
}

In the present work, $\mathrm{M}-\mathrm{TbTaO}_{4}$ and $\mathrm{M}^{\prime}-\mathrm{TbTaO}_{4}$ self-activated ceramics were prepared by solid-state reaction. It is well known that the synthesis parameters strongly influence on the degree of the crystalline order of the ceramics and in the same cases it might results in different structural arrangements [16,17]. Furthermore, the crystal structure is directly related with the luminescence performance of the materials [6]. In this work, specific conditions of temperature and time were employed to compounds crystallized in monoclinic structures with two different arrangements in agreement with the previous work by Siqueira et al. [16]. In this case, the compounds crystallize in M-fergusonite (M-type) structure with space group I2/a (\#15) when processed at high temperatures, and $\mathrm{M}^{\prime}$-fergusonite ( $\mathrm{M}^{\prime}$-type) with space group P2/a (\#13) for compounds obtained at low temperatures. The crystalline structures were investigated by X-ray diffraction (XRD) and Raman scattering. Furthermore, the photoluminescence (PL) properties of each sample were studied in detail by both PL emission and decay time measurements, in order to correlate these characteristics with the corresponding crystalline structures. Finally, we will compare the optical properties of self-activated terbium orthotantalates studied in this work with other $\mathrm{Tb}^{3+}$-doped materials.

\section{Experimental}

$\mathrm{TbTaO}_{4}$ ceramic powders were prepared by solid-state reaction. The starting materials employed were $\mathrm{Tb}_{4} \mathrm{O}_{7}$ and $\mathrm{Ta}_{2} \mathrm{O}_{5}$ ( $>99.9 \%$ Sigma-Aldrich), which were thoroughly mixed in a 
mortar according to the desired stoichiometric ratio. The experimental processing conditions were $1300^{\circ} \mathrm{C} / 6 \mathrm{~h}$ to produce $\mathrm{M}-\mathrm{TbTaO}_{4}$, and $1200{ }^{\circ} \mathrm{C} / 6 \mathrm{~h}$ to obtain $\mathrm{M}^{\prime}-\mathrm{TbTaO}_{4}$. The crystalline structures of the as-synthesized samples were studied by XRD using a Shimadzu D-6000 diffractometer with graphite monochromator and a nickel filter in the range of $10-60^{\circ} 2 \theta(15 \mathrm{~s} / \mathrm{step}$ of $\left.0.02^{\circ} 2 \theta\right)$, operating with $\mathrm{Fe}_{\alpha}$ radiation $(\lambda=0.1936 \mathrm{~nm}), 40 \mathrm{kV}$ and $20 \mathrm{~mA}$ (the results were automatically converted to $\mathrm{Cu} K_{\alpha}$ radiation for data treatment and manipulation).

Raman spectra of the as-synthesized powders were collected in backscattering configuration using an Horiba/Jobin-Yvon LABRAM-HR spectrometer with the $632.8 \mathrm{~nm}$ line of a heliumneon laser (effective power of $6 \mathrm{~mW}$ at the sample's surface) as excitation source, diffraction gratings of 600 and 1800 grooves/ $\mathrm{mm}$, Peltier-cooled CCD detector, confocal Olympus microscope (100 $\times$ objective), and experimental resolution typically $1 \mathrm{~cm}^{-1}$ for 10 accumulations of $30 \mathrm{~s}$. Appropriate interference filter for rejecting laser plasma lines, edge filter for stray light rejection were used. All resulting spectra were corrected by Bose-Einstein thermal factor [18].

The emission spectra were acquired at room temperature on a DIGIKROM480 Tzerny Turner monochromator with resolution of $1 \mathrm{~nm}$, excited by a He-Cd laser $(325 \mathrm{~nm}, 40 \mathrm{~mW})$. The luminescence signal was acquired by a photomultiplier model (R928), operating in the range from 400 to $900 \mathrm{~nm}$ or an InGaAs detector, in the range from 800 to $1700 \mathrm{~nm}$. Signal was amplified by a SRS 530 lock-in with reference signal provided by an optical chopper (SR540), operating in the range from 5 to $4000 \mathrm{~Hz}$ and collected by a computer. Luminescence decay curves were obtained in the same experimental setup of the luminescence experiments, where the SRS lock-in was substituted by a SR445A $350 \mathrm{MHz}$ Preamplifier and the amplified signal was collected by a computer. The excitation laser was pulsed by the use of a chopper, with frequencies in the range from 10 to $100 \mathrm{~Hz}$.

\section{Results and discussion}

The terbium orthotantalates produced were studied through XRD and Raman scattering and the results are presented in Fig. 1. The samples crystallized in fergusonite-type structures, but with different arrangements as a function of the synthesis temperature (Fig. 1a). At high temperatures $\left(1300^{\circ} \mathrm{C}\right)$, the powders exhibited the M-type structure, belonging to the space group I2/a $\left(C_{2 h}^{6}\right.$, \#15), with $Z=4$. On the other hand, at low temperatures $\left(1200{ }^{\circ} \mathrm{C}\right)$ the powders exhibited the $\mathrm{M}^{\prime}$-type structure, space group P2/a $\left(C_{2 h}^{4}\right.$, \#13), and $Z=2$. XRD patterns were indexed according to ICSD-109187 and

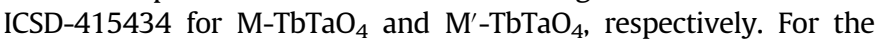
polymorphs studied in this work, it is well known that the atoms occupy different Wyckoff positions. For the ${\mathrm{M}-\mathrm{TbTaO}_{4}}_{\text {(I2/a, \#15) }}$ material, the atoms $\mathrm{Tb}$ and Ta occupy the position $4 e$ while the two oxygen occupy the 8f sites. For the $\mathrm{M}^{\prime}-\mathrm{TbTaO}_{4}$ ceramic (P2/a, \#13), the Wyckoff positions are as follows: $\mathrm{Tb}=2 \mathrm{f}, \mathrm{Ta}=2 \mathrm{e}, \mathrm{O}(1)$ and $\mathrm{O}(2)=4 \mathrm{~g}$. Due to these occupation sites, the Raman-active modes for these two systems can be decomposed according to the irreducible representation (i.r.) of the $C_{2}$ point-group. Then, using the site-group method of Rousseau et al. [19] we obtained the same distribution of the degrees of freedom at Brillouin-zone center in terms of the i.r. for the two arrangements, as following:

$\Gamma_{\text {TOTAL }}=8 A_{g}+10 B_{g}+8 A_{u}+10 B_{u}$

Fig. 1b presents the Raman spectra for the samples investigated: the blue spectrum corresponds to the $\mathrm{M}-\mathrm{TbTaO}_{4}$ ceramic, while the black spectrum is related to the $\mathrm{M}^{\prime}-\mathrm{TbTaO}_{4}$ sample. Although the materials exhibited an equal number of Ramanactive modes, they present different Raman signatures. All the 18
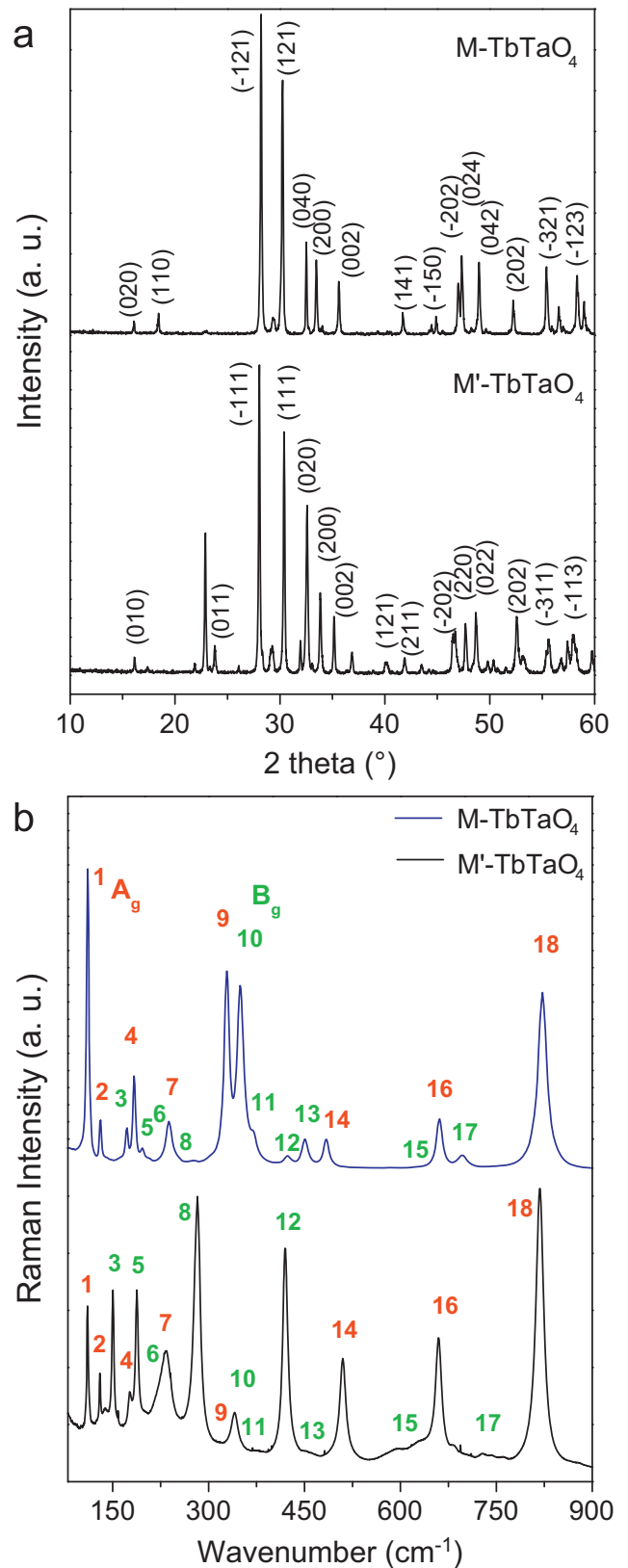

Fig. 1. (a) XRD patterns for $\mathrm{M}-\mathrm{TbTaO}_{4}$ and $\mathrm{M}^{\prime}-\mathrm{TbTaO}_{4}$ with the respective crystallographic planes indexed. (b) Raman spectra for the M-type (blue) and $\mathrm{M}^{\prime}$-type (black) compounds in the region $60-900 \mathrm{~cm}^{-1}$. The Raman-active modes are numbered for better visualization and assignment. Red numbers represent the $A_{\mathrm{g}}$ modes, while green numbers correspond to the $B_{\mathrm{g}}$ modes. (For interpretation of the references to color in this figure legend, the reader is referred to the web version of this article.)

active modes can be visualized and were numbered (Fig. 1b) for better visualization and assignment: red numbers correspond to the $A_{g}$ modes, while green numbers correspond to the $B_{g}$ modes. If we compare the spectra of $\mathrm{M}$ - and $\mathrm{M}^{\prime}-\mathrm{TbTaO}_{4}$, we can observe a change of the relative intensities of the modes through the transition from $\mathrm{M}$-fergusonite to $\mathrm{M}^{\prime}$-fergusonite. This difference could be attributed to the new structural arrangement assumed by the sample when it changes from one structure to another. Furthermore, if we observe the assignment to the active Raman modes of these fergusonite-type structures (see Fig. 1b), we can assume that the crystalline arrangement regarding the M-type structure seems to favor the $A_{g}$ modes, while the arrangement observed in $\mathrm{M}^{\prime}$-type structures seems to favor the $B_{g}$ modes. 
The main difference between the two arrangements $\mathrm{M}$ - and $\mathrm{M}^{\prime}$-type is in the coordination of Ta atom, which is four for the M-type structure and six for $\mathrm{M}^{\prime}$-type structure. Thus, in the M-type structure the Ta atoms have a tetrahedral coordination, while a distorted octahedron is observed in $\mathrm{M}^{\prime}$-type structures $[8,16]$. Furthermore, the average Ta-O distance is longer in the M-type structure, which results in a higher unit cell volume for this arrangement. Table 1 presents the lattice parameters calculated and unit cell volumes for both samples. Aiming a better comparison between the two arrangements, Fig. 2 presents a schematic representation for both structures: (a) $\mathrm{M}^{\prime}-\mathrm{TbTaO}_{4}$, and (b) $\mathrm{M}-\mathrm{TbTaO}_{4}$. The atomic distribution inside the $\mathrm{M}-\mathrm{TbTaO}_{4}$ structure is as follows: four $\mathrm{Tb}$ atoms, four Ta atoms and sixteen oxygen atoms. On the other hand, for the $\mathrm{M}^{\prime}-\mathrm{TbTaO}_{4}$ materials, the atoms inside the structure are distributed as follows: two Tb, two Ta and eight oxygen.

Now, we will discuss the photoluminescence emission behavior of the terbium orthotantalate powders. Terbium ions are efficient emission centers (mainly of green light), but generally they are used as a dopant in a host lattice, e.g., $\mathrm{GdTaO}_{4}: \mathrm{Tb}^{3+}$, $\mathrm{YTaO}_{4}: \mathrm{Tb}^{3+}$, and $\mathrm{LuTaO}_{4}: \mathrm{Tb}^{3+}[2,5,7]$. In this work, we decided to investigate the behavior of $\mathrm{M}^{-}-\mathrm{TbTaO}_{4}$ and $\mathrm{M}^{\prime}-\mathrm{TbTaO}_{4}$ materials, which can be denominated self-activated compounds. In these systems, $\mathrm{Tb}^{3+}$ ions are not dopants and new emission centers resulting of the presence of other lanthanides could not be created. The systems containing terbium ions generally have three kinds of energy transitions: $\mathrm{f}-\mathrm{f}$ intra-configurational transitions from $\mathrm{Tb}^{3+} ; 4 \mathrm{f}^{n} \rightarrow 4 \mathrm{f}^{n-1} 5 \mathrm{~d}$ inter-configurational transitions and charge transfer transitions (CT). In this last case, the $\mathrm{TaO}_{4}^{3-}$ group can absorb the excitation energy through $\mathrm{O}^{2-} \rightarrow \mathrm{Ta}^{5+}$ charge transfer transitions (called Charge Transfer Band) and transfer the energy to the $\mathrm{Tb}^{3+}$ ion.

For the $\mathrm{Tb}^{3+}$ ions with $4 \mathrm{f}^{8}$ electronic configuration, the ground states are ${ }^{7} F_{6}$. When one electron is promoted to the $5 d$ shell, it

Table 1

Lattice parameters and unit cell volumes for the terbium orthotantalates in two crystallographic arrangements ( $\mathrm{M}$ - and $\mathrm{M}^{\prime}$-type).

\begin{tabular}{|c|c|c|c|c|c|c|}
\hline \multirow{2}{*}{$\begin{array}{l}\text { Polymorphic } \\
\text { form }\end{array}$} & \multirow{2}{*}{$\begin{array}{l}\text { Synthesis } \\
\text { temperature }\left({ }^{\circ} \mathrm{C}\right)\end{array}$} & \multicolumn{4}{|c|}{ Lattice parameters } & \multirow[t]{2}{*}{$\mathbf{V}\left(\AA^{3}\right)$} \\
\hline & & a (̊) & b $(\AA)$ & c ( $(\AA)$ & $\begin{array}{l}\beta \\
\left({ }^{\circ}\right)\end{array}$ & \\
\hline $\begin{array}{l}\mathrm{M}^{\prime}-\mathrm{TbTaO}_{4} \mathrm{P} 2 / \mathrm{a} \\
(\# 13)\end{array}$ & 1200 & 5.333 & 5.489 & 5.136 & 96.7 & 150.37 \\
\hline $\begin{array}{l}\text { M-TbTaO } 42 / 2 \\
(\# 15)\end{array}$ & 1300 & 5.066 & 11.009 & 5.042 & 92.3 & 281.18 \\
\hline
\end{tabular}

gives rise to two $4 \mathrm{f}^{7} 5 \mathrm{~d}$ excitation states: the high-spin state with ${ }^{9} \mathrm{D}_{J}$ configuration or the low-spin state with ${ }^{7} \mathrm{D}_{J}$ configuration. Obviously, ${ }^{9} \mathrm{D}_{J}$ states will be lower in energy according to the Hund's rule, and the transitions between ${ }^{7} \mathrm{~F}_{6}$ and ${ }^{7} \mathrm{D}_{J}$ are spinallowed, while the transitions between ${ }^{7} \mathrm{~F}_{6}$ and ${ }^{9} \mathrm{D}_{J}$ are spinforbidden. Therefore, $\mathrm{Tb}^{3+}$ in a specific host lattice usually exhibits two groups of $4 \mathrm{f} \rightarrow 5 \mathrm{~d}$ transitions: the spin-allowed $4 \mathrm{f} \rightarrow 5 \mathrm{~d}$ transitions are strong and occur at higher energy, while the spin-forbidden $4 \mathrm{f} \rightarrow 5 \mathrm{~d}$ transitions are weak and occur at lower energy [20]. In this work, PL excitations were not carried out because the focus of our work is related to samples with practical applications on the visible (VIS) spectral range. Thus, the behavior of high energy bands related with terbium orthotantalates will be reported in future works.

Fig. 3 presents the luminescence emission spectra of the M-type (Fig. 3a) and $\mathrm{M}^{\prime}$-type structures (Fig. 3b) in the range from $450 \mathrm{~nm}$ to $750 \mathrm{~nm}\left(\lambda_{\mathrm{em}}=325 \mathrm{~nm}\right)$. He-Cd laser spectrum is also included to eliminate its contribution. The emission peaks are composed by typical transitions of $\mathrm{Tb}^{3+}$, in agreement with other $\mathrm{Tb}^{3+}$-doped materials also reported in the literature $[2,5,7]$. Excitation in the green and red regions is achieved by near UV excitation of the ${ }^{5} \mathrm{D}_{3}$ level at $325 \mathrm{~nm}$. After, non radiative decays to the ${ }^{5} \mathrm{D}_{4}$ level, transitions to the ${ }^{7} \mathrm{~F}_{J}(J=6,5,4,3,2)$ manifolds results in the emissions centered at about 490, 545, 580, 620 and $658 \mathrm{~nm}$, as identified in the Fig. 3. All the transitions observed in these spectra are result of $\mathrm{f}-\mathrm{f}$ intra-configurational transitions from $\mathrm{Tb}^{3+}$. The spin-forbidden $4 \mathrm{f} \rightarrow 5 \mathrm{~d}$ transition of $\mathrm{Tb}^{3+}$ at longer wavelengths was not observed because this transition is too weak to be observed (Fig. 3). Also, the blue emission at wavelengths below $489 \mathrm{~nm}$ originating from the ${ }^{5} \mathrm{D}_{3} \rightarrow{ }^{7} \mathrm{~F}_{J}$ transition of $\mathrm{Tb}^{3+}$ ions have not been observed. This can be explained by the well-know cross-relaxation between the ${ }^{5} D_{3}$ and ${ }^{5} D_{4}$ of $\mathrm{Tb}^{3+}$ at higher $\mathrm{Tb}^{3+}$ doping concentration $[20,21]$. As the $\mathrm{Tb}^{3+}$ concentration in $\mathrm{M}$ - and $\mathrm{M}^{\prime}-\mathrm{TbTaO}_{4}$ is high, the cross-relaxation mechanism produces rapid population of the ${ }^{5} \mathrm{D}_{4}$ state at the expense of ${ }^{5} \mathrm{D}_{3}$, giving rise to the strong green emission at around $545 \mathrm{~nm}[21]$.

Fig. 4 presents the emission spectra for the $\mathrm{M}^{\prime}-\mathrm{TbTaO}_{4}$ (black

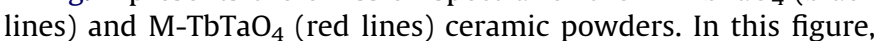
three different transitions were analyzed: ${ }^{5} \mathrm{D}_{4} \rightarrow{ }^{7} \mathrm{~F}_{6}$ (Fig. 4a), ${ }^{5} \mathrm{D}_{4} \rightarrow{ }^{7} \mathrm{~F}_{5}$ (Fig. 4b), and ${ }^{5} \mathrm{D}_{4} \rightarrow{ }^{7} \mathrm{~F}_{3}$ (Fig. 4c). The spectra were normalized for a comparison purpose between relative intensity of samples (see the intensity scales). The dominant emission under $325 \mathrm{~nm}$ excitation corresponds to the ${ }^{5} \mathrm{D}_{4} \rightarrow{ }^{7} \mathrm{~F}_{5}$ green transition. This transition has a maximum located at $543.0 \mathrm{~nm}$ in $\mathrm{M}^{\prime}$-type and at 549.2 in M-type sample. For the other a

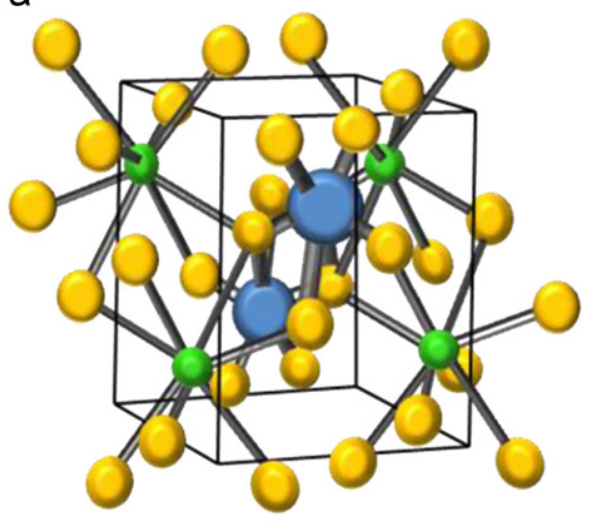

b

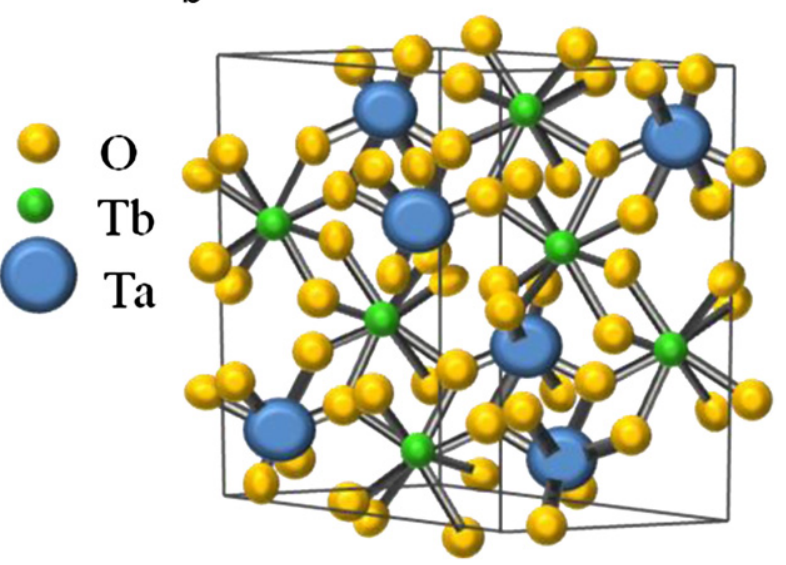

Fig. 2. Schematic representation of the basic structures to terbium orthotantalates: (a) $\mathrm{M}^{\prime}-\mathrm{TbTaO}_{4}$; (b) $\mathrm{M}^{\prime} \mathrm{TbTaO}_{4}$. 

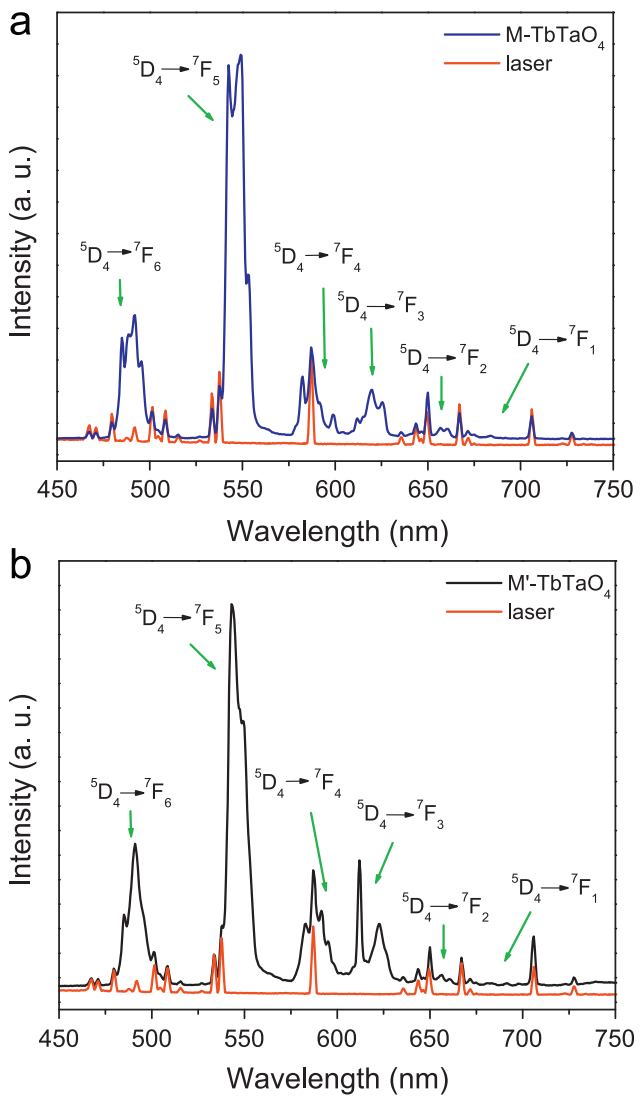

Fig. 3. Photoluminescence emission spectra in the range $450-750 \mathrm{~cm}^{-1}$ with

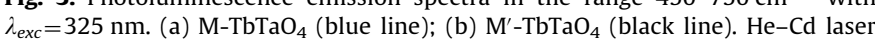
lines are also shown (red line) for comparison purposes. (For interpretation of the references to color in this figure legend, the reader is referred to the web version of this article.)

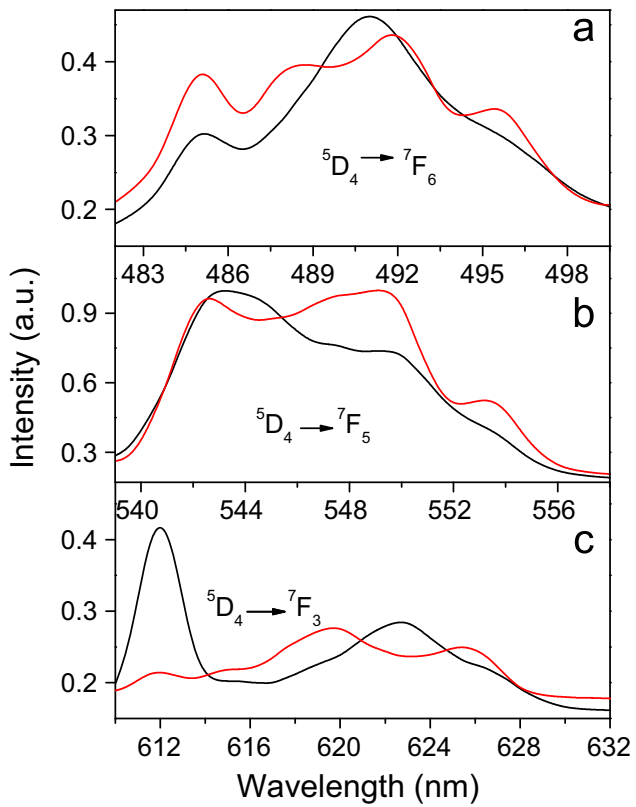

Fig. 4. Normalized emission spectra for $\mathrm{M}^{\prime}-\mathrm{TbTaO}_{4}$ (black lines) and $\mathrm{M}-\mathrm{TbTaO}_{4}$ (red lines). (a) ${ }^{5} \mathrm{D}_{4} \rightarrow{ }^{7} \mathrm{~F}_{6}$ transition; (b) ${ }^{5} \mathrm{D}_{4} \rightarrow{ }^{7} \mathrm{~F}_{5}$ transition; (c) ${ }^{5} \mathrm{D}_{4} \rightarrow{ }^{7} \mathrm{~F}_{3}$ transition. (For interpretation of the references to color in this figure legend, the reader is referred to the web version of this article.)

transitions $\left({ }^{5} \mathrm{D}_{4} \rightarrow{ }^{7} \mathrm{~F}_{6}\right.$ and $\left.{ }^{5} \mathrm{D}_{4} \rightarrow{ }^{7} \mathrm{~F}_{3}\right)$, the maxima can also be easily visualized in Fig. 4 . We can observe that some distinction in the peak position occurs, and blue shifts could be observed in the $\mathrm{M}^{\prime}$-type spectra in comparison with the M-type spectra. A significant difference between the relative intensity is observed for the ${ }^{5} D_{4} \rightarrow{ }^{7} F_{3}$ transitions (see Fig. 4c). We believe that these shifts in the peak positions as well as all the variation in spectral shape and relative intensity could be caused by the differences in the crystallographic structures. According to the literature, the structural characteristics of the $\mathrm{M}^{\prime}$-type arrangements favor the crystalline field that result in a more efficient energy transfer for the $\mathrm{M}^{\prime}$-type when compared to the M-type samples [8].

PL decay curves were obtained from kinetic measurements and they are also an important parameter for luminescence materials. The decay of the PL intensity was monitored after the excitation interruption and, on the basis of the exponential formula, the fluorescence lifetime was determined, i.e., the time after which the intensity is dropped to $\frac{1}{e}$ from the initial value. Fig. 5 shows the PL decay curves for $\mathrm{M}^{-\mathrm{TbTaO}_{4}}$ (Fig. 5a) and $\mathrm{M}^{\prime}-\mathrm{TbTaO}_{4}$ (Fig. 5b). The monitored emission wavelength was $547 \mathrm{~nm}$. The transition ${ }^{5} \mathrm{D}_{4} \rightarrow{ }^{7} \mathrm{~F}_{5}$ was chosen since it presents the best signal/noise relation. Both decay curves can be fitted by single-exponential function:

$I=I_{0} \exp \left(\frac{-t}{\tau}\right)$

where $I_{0}$ is the initial intensity at $t=0$ and $\tau$ is the lifetime. The insets in Fig. 5 show the luminescence decay in logarithmic scale. As the best fits for our samples were the first-order exponential curves, it can be considered that the terbium ions occupy only one symmetry site $C_{2}$ in both structures [22]. Such result is also in agreement with results from Raman scattering, which assumes a unique symmetry as a basis for group theory calculations. Fluorescence lifetimes for $\mathrm{M}-\mathrm{TbTaO}_{4}$ and $\mathrm{M}^{\prime}-\mathrm{TbTaO}_{4}$ ceramic powders were
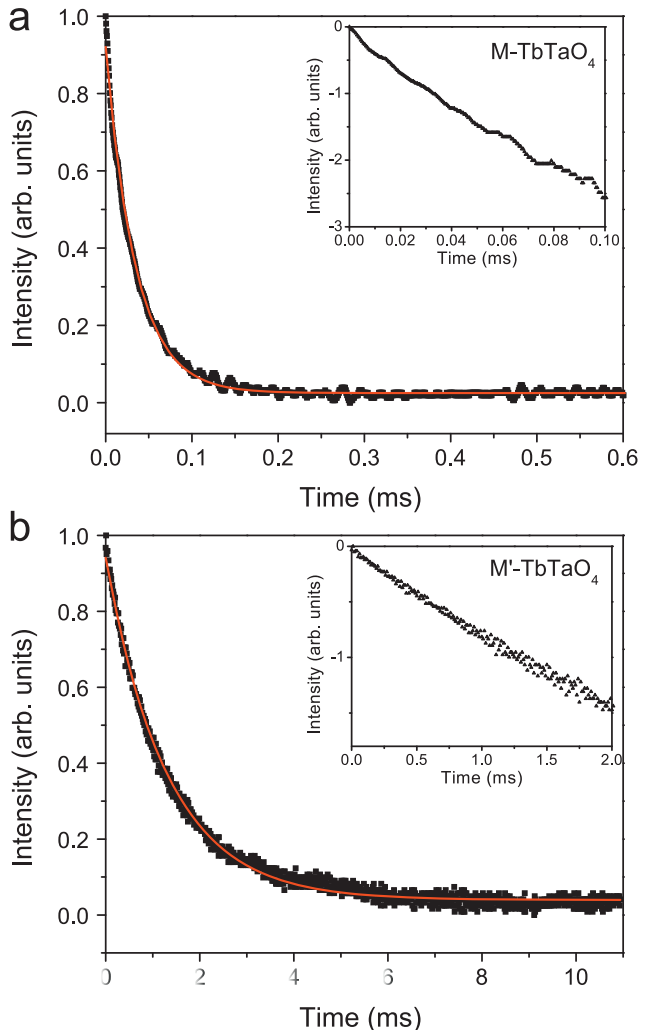

Fig. 5. Decay curves for the monitored emission wavelengths $547 \mathrm{~nm}$ $\left(\lambda_{\text {exc }}=325 \mathrm{~nm}\right)$. (a) Decay curve for $\mathrm{M}-\mathrm{TbTaO}_{4}$; (b) decay curve for $\mathrm{M}^{\prime}-\mathrm{TbTaO}_{4}$. The curves were fitted by single-exponential function (red lines) and the insets show the decay curves in logarithmic scale. (For interpretation of the references to color in this figure legend, the reader is referred to the web version of this article.) 
Table 2

Comparison between the green peak positions, half width at half maxima (HWHM) and fluorescence lifetimes for the terbium orthotantalates and other lanthanide tantalate materials doped with $\mathrm{Tb}^{3+}$.

\begin{tabular}{|c|c|c|c|c|c|}
\hline Sample & $\begin{array}{l}\text { Green Peak } \\
\text { position } \\
(\mathrm{nm})\end{array}$ & $\begin{array}{l}\text { Excitation } \\
\text { radiation } \\
(\mathbf{n m})\end{array}$ & $\begin{array}{l}\text { HWHM } \\
\text { (nm) }\end{array}$ & $\begin{array}{l}\text { Lifetime } \\
(\tau)\end{array}$ & Reference \\
\hline $\mathrm{M}-\mathrm{TbTaO}_{4}$ & 549.2 & 325 & 11.0 & $33.40 \mu \mathrm{s}$ & This work \\
\hline $\mathrm{M}^{\prime}-\mathrm{TbTaO}_{4}$ & 543.0 & 325 & 11.0 & $1.25 \mathrm{~ms}$ & This work \\
\hline $\mathrm{M}^{\prime}-\mathrm{GdTaO}_{4}: \mathrm{Tb}^{3+}$ & 547.0 & 245 & 11.5 & $1.02 \mathrm{~ms}$ & [5] \\
\hline $\mathrm{M}^{\prime}-\mathrm{LuTaO}_{4}: \mathrm{Tb}^{3+}$ & 547.0 & 378 & 11.5 & $1.04 \mathrm{~ms}$ & [2] \\
\hline
\end{tabular}

determined as $(33.4 \pm 0.9) \mu$ s and $(1.25 \pm 0.07) \mathrm{ms}$, respectively. Error in the lifetime results is estimated of about $10 \%$. The lifetime of the $\mathrm{M}^{\prime}-\mathrm{TbTaO}_{4}$ sample is expressively higher than that for the $\mathrm{M}-\mathrm{TbTaO}_{4}$ ceramic. This can be attributed to the crystal field of the $\mathrm{M}^{\prime}$-type material, as already discussed previously.

Table 2 presents a comparison of some optical properties of self-activated orthotantalates studies in this work (M- and $\mathrm{M}^{\prime}$-type) and other orthotantalates materials doped with $\mathrm{Tb}^{3+}$ $\left(\mathrm{M}^{\prime}-\mathrm{GdTaO}_{4}: \mathrm{Tb}^{3+}\right.$ and $\left.\mathrm{M}^{\prime}-\mathrm{LuTaO}_{4}: \mathrm{Tb}^{3+}\right)$ for comparison purposes. It is important to mention that all compounds presented in Table 2 are in a powder form. This is relevant since it was already shown that fluorescence lifetime of $\mathrm{Tb}^{3+}$ can be affected by kind of host (crystals, films, fibers, powders), which can modify the crystalline field and, consequently, the lifetimes. For instance, the $\mathrm{GdTaO}_{4}: \mathrm{Tb}^{3+}$ phosphor presents lifetime given by $1.02 \mathrm{~ms}, 0.79 \mathrm{~ms}$ and $0.901 \mathrm{~ms}$ in powder, film and single crystal forms, respectively $[5,10]$. According to Table 2 , the self-activated $\mathrm{M}^{\prime}-\mathrm{TbTaO}_{4}$ samples present the higher lifetimes, while the $\mathrm{M}-\mathrm{TbTaO}_{4}$ exhibits shorter lifetimes. It can be concluded that even in compounds where new emission centers are not created (by the addition of other lanthanides), i.e., in self-activated materials, efficient emission can be observed. In accordance with our studies, we can suggest that the new self-activated materials (like $\mathrm{M}^{\prime}-\mathrm{TbTaO}_{4}$ ) can be a potential green luminescent material for applications in luminescent devices.

\section{Conclusions}

Terbium orthotantalates ( $\mathrm{M}$ - and $\mathrm{M}^{\prime}$-type structures) were successfully synthesized by solid-state reaction. XRD and Raman results have proved the crystallinity of the samples and all the 18 Raman-active modes were identified and assigned, in agreement with group theory calculations. For the first time, the behavior of $\mathrm{Tb}^{3+}$ ions in self-activated orthotantalates was reported. XRD, Raman scattering and PL measurements (emission and decay curves) have shown that our samples present different structures and, consequently, different optical properties. The emission spectra of the ceramic powders under $325 \mathrm{~nm}$ excitation were obtained and the emission peaks are composed by typical transitions of $\mathrm{Tb}^{3+}$ from ${ }^{5} \mathrm{D}_{4}$ level to ${ }^{7} \mathrm{~F}_{J}(J=6,5,4,3,2)$. Differences in the Stark splitting and fluorescence lifetimes of $\mathrm{M}$ - and $\mathrm{M}^{\prime}-\mathrm{TbTaO}_{4}$ were evidenced. PL emission spectra $\left(\lambda_{\text {exc }}=325 \mathrm{~nm}\right)$ exhibited green emission with maximum position at around 549.2 and $543.0 \mathrm{~nm}$ for $\mathrm{M}$ - and $\mathrm{M}^{\prime}$-type structures, respectively, corresponding to the ${ }^{5} \mathrm{D}_{4} \rightarrow{ }^{7} \mathrm{~F}_{5}$ transitions. The fluorescence lifetimes were determined as $33.4 \mu \mathrm{s}$ for $\mathrm{M}-\mathrm{TbTaO}_{4}$ and $1.25 \mathrm{~ms}$ for $\mathrm{M}^{\prime}-\mathrm{TbTaO}_{4}$. It was verified that $\mathrm{Tb}^{3+}$ ions occupy only onesymmetry site $\left(C_{2}\right)$ in the two different arrangements, in agreement with our spectroscopic results. It can be concluded that in the new self-activated $\mathrm{TbTaO}_{4}$ materials efficient emission can be observed. Furthermore, $\mathrm{M}^{\prime}$-type samples are the most suitable for luminescent devices and they could be a potential green luminescent materials due to the strongest emission if compared with the M-type fergusonite.

\section{Acknowledgements}

The authors acknowledge the financial support from CNPq, FINEP and FAPEMIG.

\section{References}

[1] P.F.S. Pereira, M.G. Matos, L.R. Avila, E.C.O. Nassor, A. Cestari, K.J. Ciuffi, P.S. Calefi, E.J. Nassar, J. Lumin. 130 (2010) 488.

[2] W. Liu, Q. Zhang, L. Ding, D. Sun, J. Luo, S. Yin, J. Alloys Compd. 474 (2009) 226

[3] E.-J. Popovici, M. Nazarov, L. Muresan, D.Y. Noh, L.B. Tudoran, E. Bica, E. Indrea, J. Alloys Compd. 497 (2010) 201.

[4] S. Bangaru, G. Muralidharan, J. Lumin. 130 (2010) 343.

[5] M. Gu, L. Zhu, X. Liu, S. Huang, B. Liu, C. Ni, J. Alloys Compd. 501 (2010) 371.

[6] E.-J. Popovici, M. Nazarov, L. Muresan, D.Y. Noh, M. Morar, E. Bica, E. Indrea, Radiat. Meas. 45 (2010) 300.

[7] I. Arellano, M. Nazarov, C.C. Byeon, E.-J. Popovici, H. Kim, H.C. Kang, D.Y. Noh, Mater. Chem. Phys. 119 (2010) 48

[8] H. Zhang, Y. Wang, L. Xie, J. Lumin. 130 (2010) 2089.

[9] K. Tonooka, O. Nishimura, J. Lumin. 87-89 (2000) 679.

[10] W. Liu, Q. Zhang, W. Zhou, C. Gu, S. Yin, IEEE Trans. Nucl. Sci. 57 (2010) 1287.

[11] L.H. Brixner, H.-Y. Chen, J. Electrochem. Soc. 130 (1983) 2435.

[12] B. Li, Z. Gu, J. Lin, M.-Z. Su, Mater. Res. Bull. 35 (2000) 1921.

[13] B. Li, Z. Gu, J. Lin, M.-Z. Su, J. Mater. Sci. 35 (2000) 1139.

[14] L.H. Brixner, J. Electrochem. Soc. 111 (1964) 690

[15] M. Nazarov, D.Y. Noh, in: New Generation of Europium and Terbium Activated Phosphors: From syntheses to applications, Pan Stanford, USA, 2011, p. 146.

[16] K.P.F. Siqueira, G.B. Carvalho, A. Dias, Dalton Trans. 40 (2011) 9454.

[17] I. Hartenbach, F. Lissner, T. Nikelski, S.F. Meier, H.M-. Munz, T. Schleid, Z. Anorg. Allg. Chem. 631 (2005) 2377.

[18] W. Hayes, R. Loudon, Scattering of Light by Crystals, Wiley, New York, 1978.

[19] D.L. Rousseau, R.P. Bauman, S.P.S. Porto, J. Raman Spectrosc. 10 (1981) 253.

[20] C. Duan, Z. Zhang, S. Rösler, S. Rösler, A. Delsing, J. Zhao, H.T. Hintzen, Chem. Mater. 23 (2011) 1851

[21] D.J. Robbins, B. Cockayne, B. Lent, J.L. Glasper, Solid State Commun. 20 (1976) 673.

[22] J.L. Ferrari, A.M. Pires, M.R. Davolos, Mater. Chem. Phys. 113 (2009) 587. 